\title{
Replacement of Health Monitoring System and Health Evaluation for Jinan Yellow River Cable-stayed Bridge
}

\author{
Ze-Ying YANG, Ting-Ting TAN, Yang-Yudong LIU, Ming-Hao SUN
}

School of Civil and Hydraulic Engineering, Shandong University, Jinan, Shandong, 250061, China

Keywords: Cable-stayed bridge, Health monitoring, Optical fiber grating sensor, Health status evaluation.

\begin{abstract}
In order to understand the behavior of Jinan Yellow River Bridge more accurately and evaluate the bridge health, we change the sensors of the health monitoring system so that the data collected are more detailed and comprehensive. The monitoring data are analyzed synthetically. And then, based on this, the health condition of the Jinan Yellow River cable-stayed Bridge was evaluated.
\end{abstract}

\section{Background of Project}

Jinan Yellow River Highway Bridge is located in the northern suburb of Jinan City, Shandong Province. Bridge span $2023.44 \mathrm{~m}$, its main span is $488 \mathrm{~m}$ and approach bridge is $1535.44 \mathrm{~m}$. The main bridge is 5 holes' continuous prestressed concrete cable-stayed bridge, whose towers and cable plane are both double. Figure 1 shows the overall layout of the Jinan Yellow River Highway Bridge.

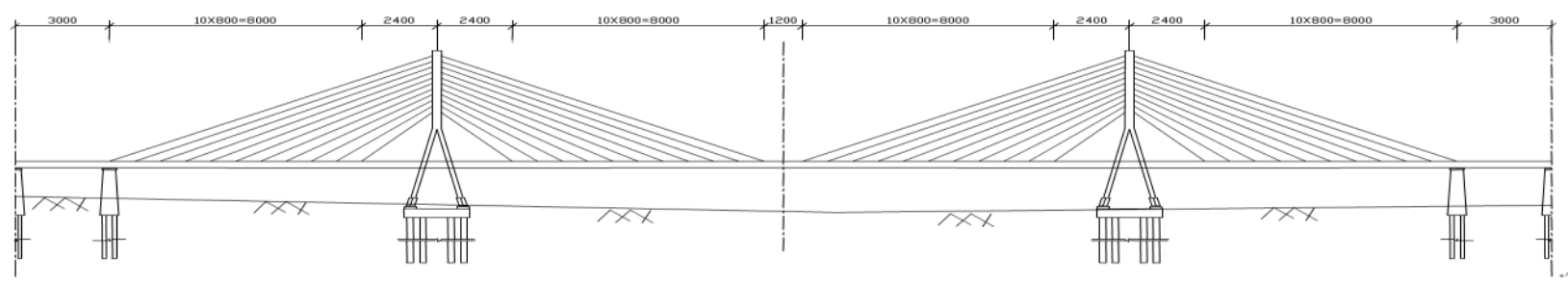

Fig.1 The overall layout of the Jinan Yellow River Highway Bridge

\section{The Yellow River Bridge Health Monitoring System's Replacement}

By 2014, the fiber grating modulation demodulator (containing IPC) had completely paralyzed and it was beyond repair, so we replaced the new demodulation instrument and IPC. In July 2015, we replaced the strain and acceleration sensors with fiber grating sensors. The installation position of sensor and replacement is the same as before.

\section{Main Beam's Strain Monitoring Subsystem}

Figure 2 shows the measuring position of the main girder stress monitoring point. The monitoring section is near the mid-span and the expansion joints of the main bridge's south side. In the mid-span and southern side span, the sensor's arrangement and numbers are shown in Figure 3, including the temperature compensation sensor of $2 \#, 6 \#, 9 \#$ and $12 \#$. These sensors are used to eliminate the effects caused by temperature factors.

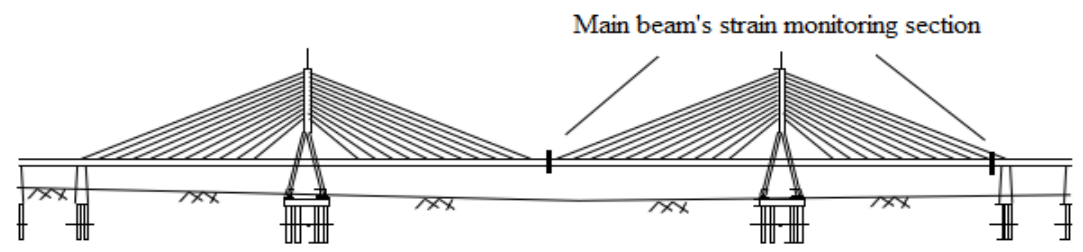

Fig.2. The measuring position of the main girder stress monitoring point 


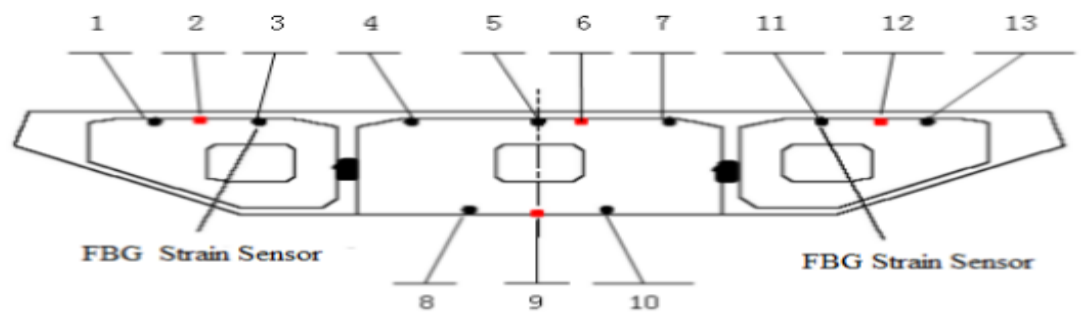

Fig.3 FBG strain sensors layout of the mid-span and southern side span

When the strain sensor is installed, we need to connect sensors in series. Strain sensors and temperature sensors are mounted on the base and the metal plate respectively, as shown in Figure 4.

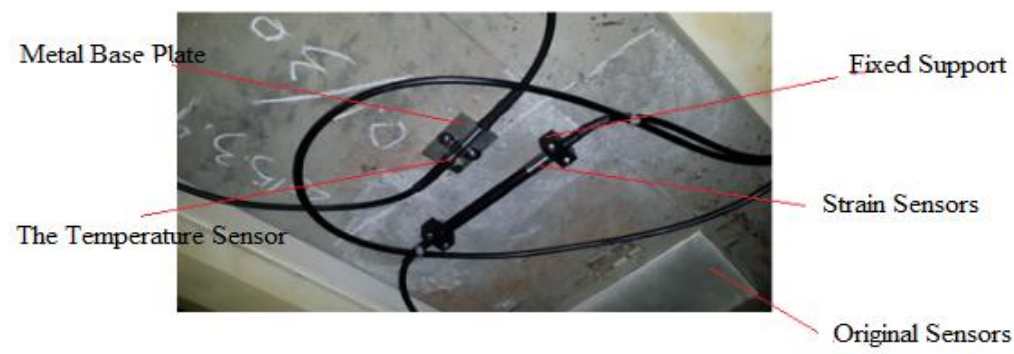

Fig.4 The strain sensors after replacement

\section{Main Beam's Vibration Monitoring Subsystem}

Main beam's dynamic stress monitoring uses fiber grating vibration sensor, which has no zero drift, good dynamic characteristics and immune to electromagnetic interference effects. Five vibration measurement sections of the main beam are arranged in the min-span of side span, min-span and quarter-span. The southern min-span is also arranged in a longitudinal vibration sensor. There are a total of 16 vibration sensors and 5 temperature compensation sensor, as shown in Figure 5 and 6.

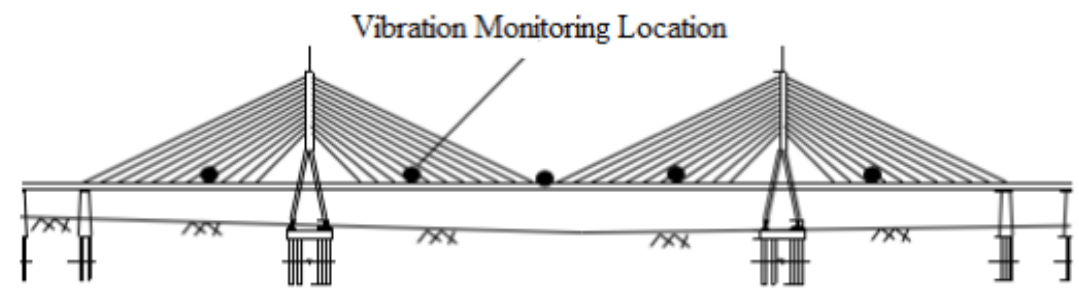

Fig.5 The longitudinal layout of vibration measurements

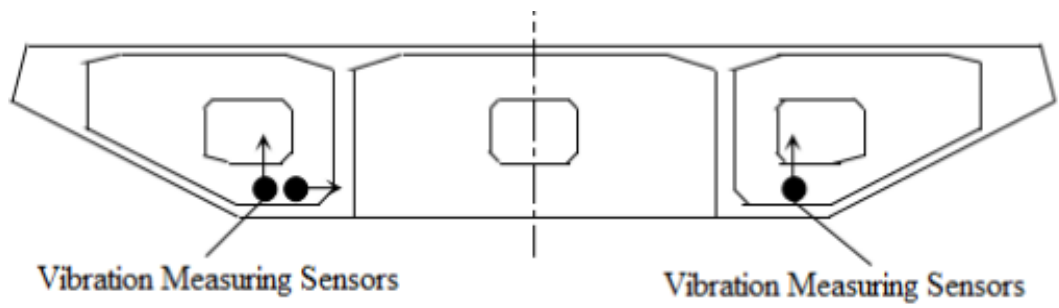

Fig.6. The transverse layout of vibration measurements

To avoid vibration sensor from accidental damage, the vibration sensor needs adding an external housing protection, that must be marked with the direction of sensor test to check and replace in late period, as shown in Figure 7 and 8. 
SEN-AL The acceleration sensor

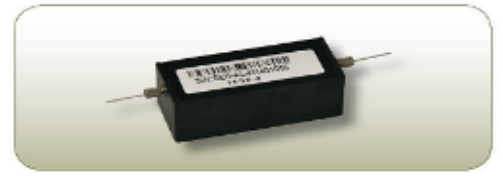

SEN-AL FBG acceleration sensors are used to monitor low frequency vibration acceleration. Single sensor is a onedimensional direction, can be combined into a multidimensional acceleration sensor through the three-dimensional scaffold . Responsiveness and acquisition speed of the FBG acceleration sensor is extremely fast, multi-dimensional clock synchronization can be achieved, and it can also achieve more clock synchronization for testing momentary gesture.

\begin{tabular}{|c|c|c|}
\hline \multirow{4}{*}{$\begin{array}{c}\text { Performance } \\
\text { indicators }\end{array}$} & Project & Parameters \\
\cline { 2 - 3 } & Standard Range & $2 \mathrm{G}$ \\
\cline { 2 - 3 } & Accuracy & $2 \% \mathrm{~F} . \mathrm{S}$ \\
\cline { 2 - 3 } & Resolution & $0.1 \%$ F.S (Match SEN-01demodulator) \\
\cline { 2 - 3 } & Size & $33 \mathrm{~mm}^{*} 36 \mathrm{~mm}^{*} 61.5 \mathrm{~mm}$ \\
\cline { 2 - 3 } & Measuring the frequency domain & $10 \mathrm{~Hz}$ \\
\cline { 2 - 3 } & Eigenfrequency & $>2 \mathrm{KHz}$ \\
\hline \multicolumn{2}{|c|}{ Operating temperature } & $-30^{\circ} \mathrm{C} \sim 85^{\circ} \mathrm{C}$ \\
\hline \multicolumn{2}{|c|}{ Equipment (optional) } \\
\hline \multicolumn{2}{|c|}{ SEN-01-1000Hz } & 2 Channel demodulator(1000Hz) \\
\hline \multicolumn{2}{|c|}{ SEN-P02 } & Portable demodulator \\
\hline
\end{tabular}

Fig.7 The vibration sensors

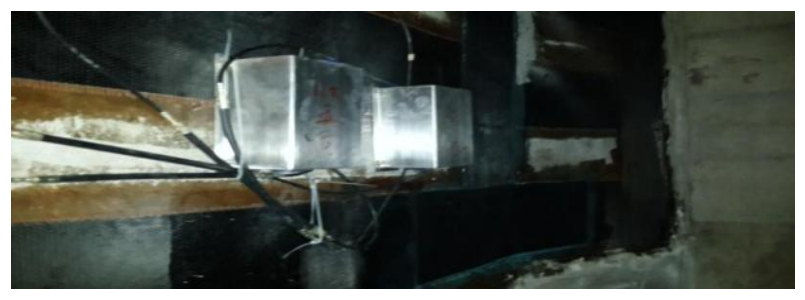

Fig.8 The vibration sensor after replacement

\section{Arrange the Total Cable}

When the strain and vibration sensors are installed, we start to connect and arranged the bus. We need to locate each fiber corresponds to the channel in the collective line box of monitoring room, and then through the jumpers connect the fiber's jack to the demodulator's socket accordingly, as shown in Figure 9. Finally, debug the data conversion software of demodulation instrument on the computer that is connected to the demodulator, and display real-time strain and acceleration values monitored on the computer screen, as shown in Figure 10 and 11. Then store the data in the corresponding database for analysis and processing.

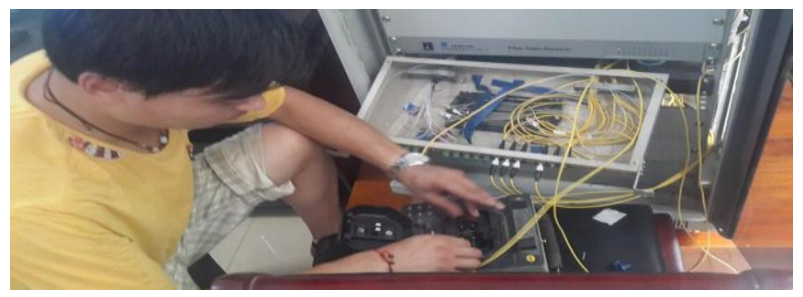

Fig.9 Connect the optical fiber in the box

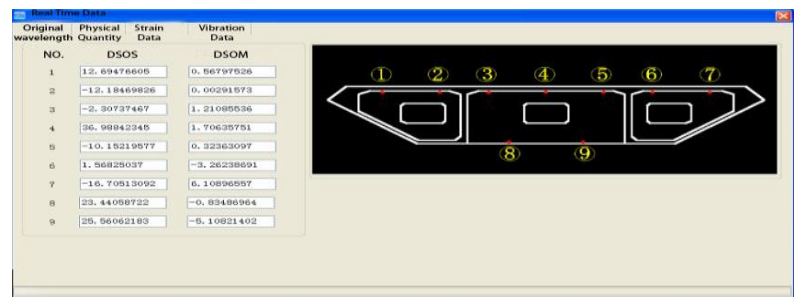

Fig.10 The real-time strain values of box girders

(DSOS-dynamic strain of side span, DSOM-dynamic strain of mid span) 


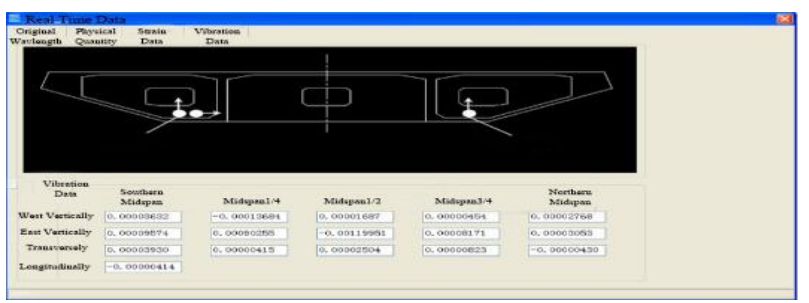

Fig. 11 The real-time vibration value of the box girder

\section{The Analysis of the Monitoring Results}

Since the strain of mid-span is the largest in the cable-stayed bridge, so is the vibration and displacement, the mid-span is regarded as the main reference point therefore. The monitoring data by software in November 2015 are analyzed as follows.

\section{The Analysis of the Vibration Monitoring}

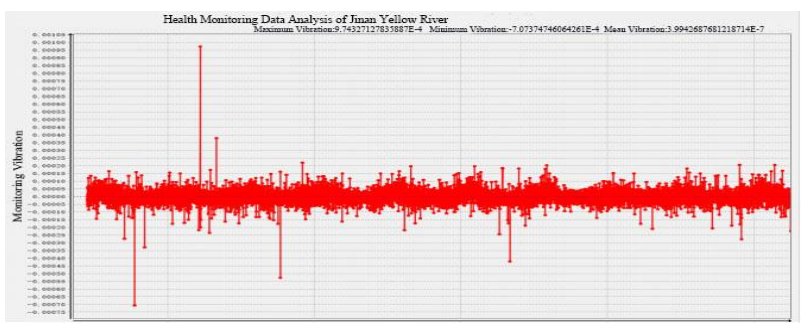

Fig. 12 The longitudinal acceleration in the mid-span

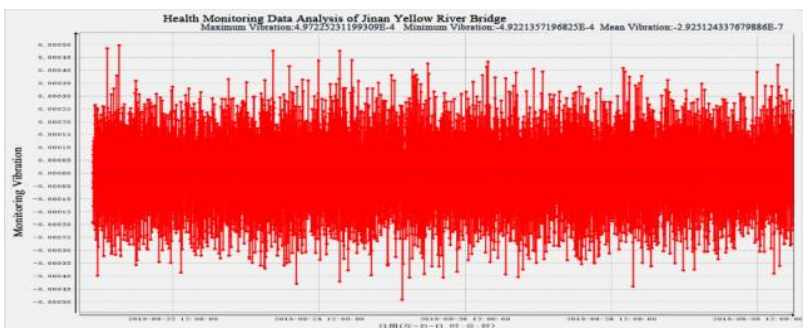

Fig.13 The vertical acceleration of western side in the box girder

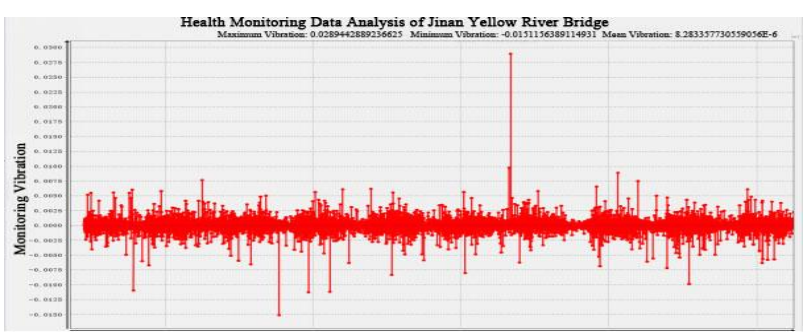

Fig.14 The vertical eastern side in the box girder

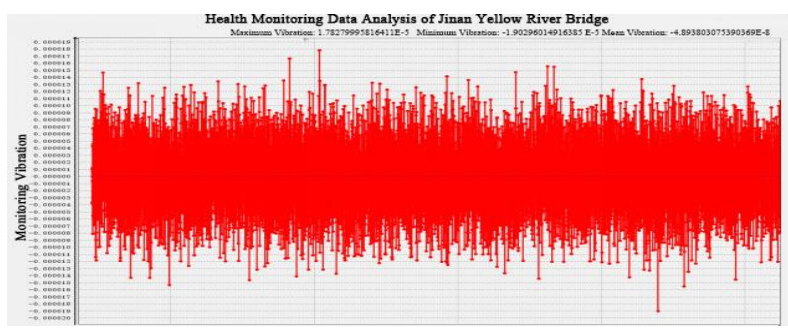

Fig.15 The transverse acceleration in box girder lateral

From Figure 12 to 15, we can see if the noise (the acceleration increases abruptly in the figure ) is ignored, the maximum of longitudinal acceleration does not exceed $0.0003 \mathrm{~g}$ ( $\mathrm{g}$ is the gravitational 
acceleration $9.8 \mathrm{~m} / \mathrm{s} 2$, the same below). Longitudinal stiffness of the bridge is still very large, able to meet the needs of normal use. The western side's maximum acceleration of western box girder does not exceed $0.0005 \mathrm{~g}$ and eastern side's does not exceed $0.01 \mathrm{~g}$. The eastern and western sides of box beam are quite different in the acceleration, indicating box girder damaged and concrete used in the bridge changed to some degree after a long period of operation, causing torsional stiffness decreased. The maximum of horizontal acceleration is at most $0.00002 \mathrm{~g}$, declaring that the bridge tower and bearing work in good condition. Overall, due to the longer time of use, there have been some changes in the bridge structure and the overall stiffness has declined, but it's still in normal use. And the bridge still needs to strengthen the periodic maintenance.

\section{The Analysis of the Strain Monitoring}

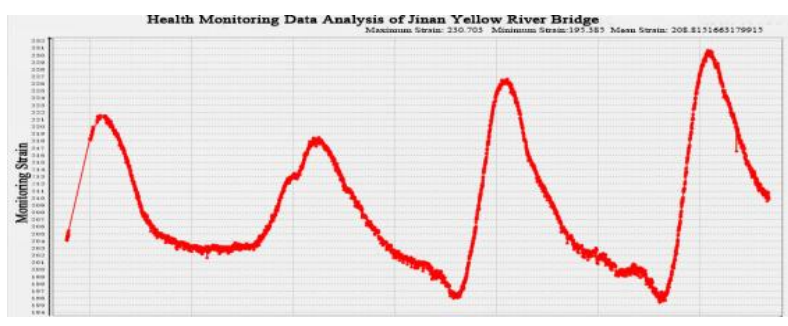

Fig. 16 Strain in the mid-span

Since the strain of mid-span is the largest in cable-stayed bridge's box girder, we just analyze mid-span' strain. Figure 16 shows that the maximum strain is 230 times micro-strain, indicating that main beam has produced some deformation, due to the impact of external load and concrete's own shrinkage and creep, as well as the loss of box beam's prestress. But the main beam can still meet the needs of normal use.

\section{The Analysis of the Displacement Monitoring}

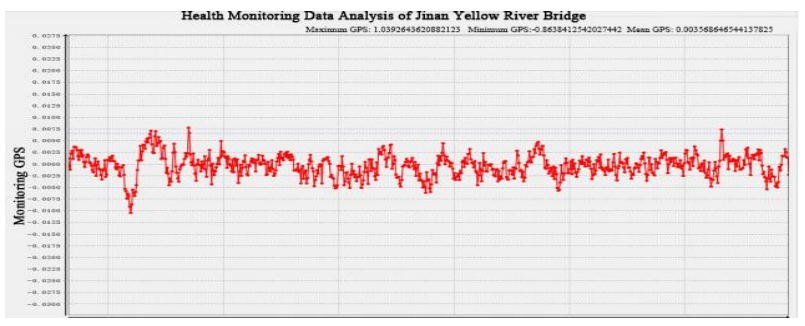

Fig.17. The longitudinal coordinates of the cable tower top

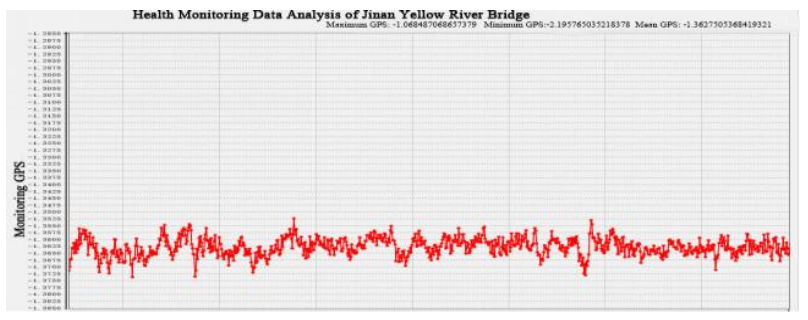

Fig.18 The transverse coordinates of the cable tower top

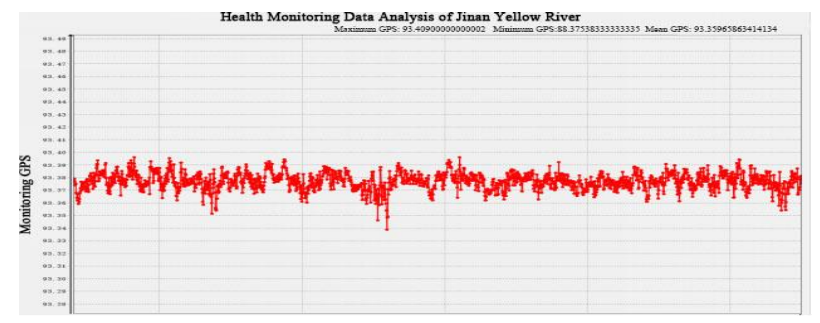

Fig.19. The coordinates of the cable tower top 


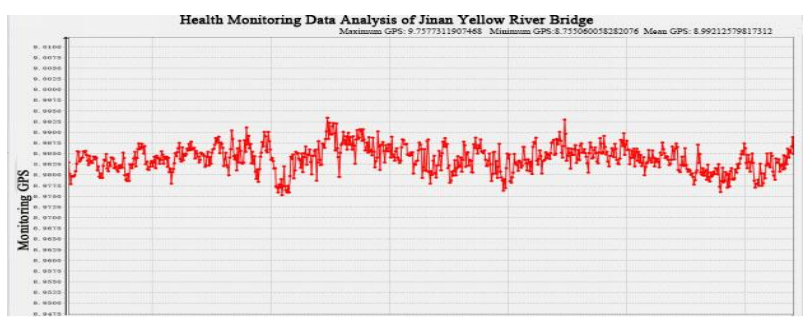

Fig.20 The longitudinal coordinates in the mid-span of box girder

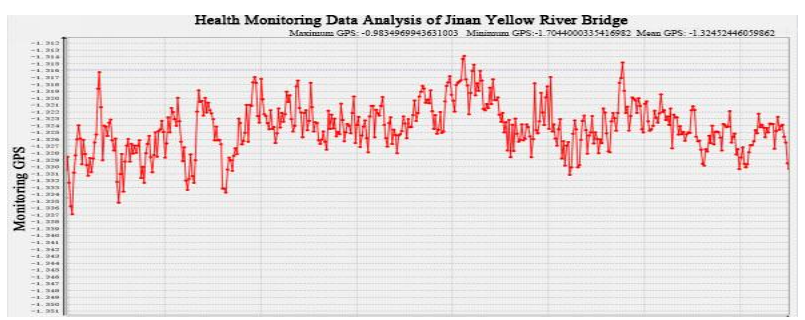

Fig.21 The transverse coordinates in the mid-span of box girder

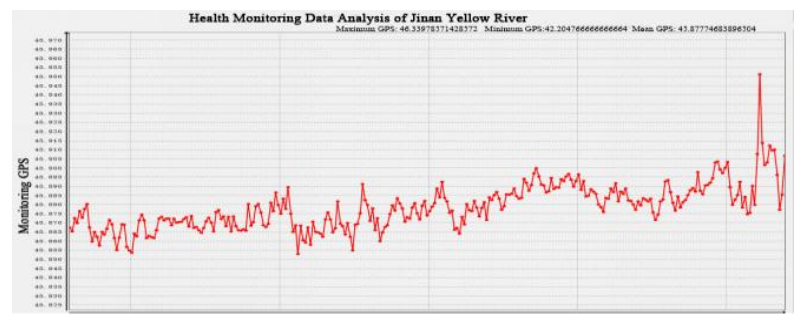

Fig. 22 The vertical coordinates in the mid-span of box girder

As can be seen from Figure 17 to 22, the tower and mid-span of box girder locate basically steadily with no major displacement amplitude. This indicates that the stiffness of cable tower is pretty large and the tower works in good condition. What's more, the intensity of stay cables can be required to meet current conditions without replacement.

On the whole, because of the reasonable structure, regular maintenance and cable timely replaced, the health condition is still good even after a long period of work. However, as a result of the fatigue of reinforced and the loss of prestress increasing with time, the bridge needs to increase the frequency of maintenance and strengthen efforts to maintenance at the later stage.

\section{Conclusion}

(1) The health monitoring system is very important for the large-scale bridge working in a long time, so the bridge can be easily and timely monitored. Besides, we can be able to find out the operational status of the bridge in time, providing accurate analysis and forecast of injury and disease. This can effectively prevent serious collapse accident of the bridge.

(2) Based on the monitoring data of Jinan Yellow River Bridge in research, we can find that the bridge is currently in good health. It's structure is stable and it can basically meet the current needs of normal use, although the bridge was built in an earlier time and traffic is heavy. This is mainly due to the addition of limit carrier on both bridge heads, cable replacement and routine maintenance properly. Moreover, paste carbon cloth can strengthen the girder.

\section{Acknowledgments}

This Project was funded by the Technology Innovation Plan in traffic of Shandong Province (2012A15), and the China Postdoctoral Science Foundation (2013M531560), and the Science \& Technology Development Projects of Shandong Province(2014GSF120015) 


\section{References}

1. Jianfeng Fan. Research on Intelligent Bridge Health Assessment. Wuhan University of Technology. 2006

2. Fanglin Huang, Wang Xuemin and Chen Zhengqing. Advances in Large Bridge Health Monitoring. China Railway Science .2005

3. Liang $\mathrm{Xu}$, Guo Jingjun and Dai Lianjun. Real-time monitoring data analysis based on GPS (RTK technology) displacement of Humen Bridge. Engineering survey. 2001

4. Jingjun Guo, Dai Lianjun and Lu Yunchuan. Study on Humen Bridge GPS (RTK) Real-time monitoring of the displacement method. Bulletin of Surveying and Mapping.2000

5. Aiqun Li, Changqing Miu and Zhaoxia Li. Research on Runyang Yangtze River Bridge' Structural Health Monitoring System. Southeast University. 2003

6. Yong Zhu, Yumei Fu and Weimin Chen. Health Monitoring System of Dafosi Yangtze River Bridge. China Civil Engineering Journal. 2005

7. Jun Liu. Integration and design of Bridge health monitoring system [D]. Wuhan: Wuhan University of Technology, 2010.

8. Deming Feng. Research on bridge health monitoring system based on wireless sensor network [D]. Changsha: Changsha University, 2012.

9. Shuang Lu and Yongshui Zhang. Methods application of Bridge Health Monitoring Assessment [J]. Journal Of Chongqing Jiaotong University, 2013,32 (3): 1-3. 